\title{
Distribuição, abundância e diversidade de Simuliidae (Diptera) em uma bacia hidrográfica impactada no sul do Brasil
}

\author{
Milton Norberto Strieder ${ }^{1}$, José Eloy dos $\operatorname{Santos}^{1} \&$ Emerson Monteiro Vieira ${ }^{2}$
}

${ }^{1}$ Laboratório de Entomologia, Ciências da Saúde, Universidade do Vale do Rio dos Sinos. Av. Unisinos 950, 93022-000 São Leopoldo-RS, Brasil.strieder@unisinos.br

${ }^{2}$ Laboratório de Ecologia de Mamíferos, Universidade do Vale do Rio dos Sinos.

\begin{abstract}
Distribution, abundance and diversity of Simuliidae (Diptera) in an impacted watershed in southern Brazil. This study was carried out in two areas with different degrees of environmental degradation in the Caí river basin, in Rio Grande do Sul. One sampling area is less altered and the other is strongly impaired by organic pollutants from avian and swine production. The larvae and pupae of simulids were collected using artificial substrates that remain submersed in streams for 14 days. In all sampling sites water was collected simultaneously for physical-chemical and microbiological analysis. In the less disturbed area eleven species were collected with the following frequencies: Psaroniocompsa incrustata (42.95\%), P. auripellita (17.66\%), Chirostilbia pertinax (16.86\%), Inaequalium subclavibranchium $(8.43 \%)$, I. nogueirai $(5.80 \%)$, P. anamariae (3.69\%), I. clavibranchium (1.58\%), C. riograndense (0.92\%), Lutzsimulium hirticosta $(0.92 \%)$, I. botulibranchium $(0.79 \%)$, Thyrsopelma itaunense $(0.40 \%)$. In the more disturbed area only six species were collected: C. pertinax (84.31\%), C. riograndense (7.52\%), T. itaunense (4.68\%), P. incrustata (2.94\%), I. subclavibranchium $(0.33 \%)$, Ectemnaspis dinellii $(0.22 \%)$. The concentrations of nitrate and nitrite had the greatest variations and allowed us to distinguish the sampling sites by to water quality. The nitrate concentration was significatively correlated with the occurrence of $C$. pertinax $\left(\mathrm{r}^{2}=0,54 ; \mathrm{P}<0,03\right)$ and $T$. itaunense $\left(\mathrm{r}^{2}=0,55 ; \mathrm{P}<0,03\right)$ while the nitrite concentration with $C$. riograndense $\left(\mathrm{r}^{2}=0,64 ; \mathrm{P}<0,02\right)$. These data can be useful for integrated black flies control programs, currently in use in at least 170 municipalities of Rio Grande do Sul.
\end{abstract}

KEYWORDS. Black flies; Nematocera; Neotropical; organic pollution; Simuliidae.

RESUMO. Distribuição, abundância e diversidade de Simuliidae (Diptera) em uma bacia hidrográfica impactada no sul do Brasil. Este estudo foi realizado na bacia do rio Caí, no Rio Grande do Sul, em duas áreas com diferentes estados de conservação ambiental: uma fortemente alterada pela intensa avicultura e suinocultura e outra mais conservada. Para padronizar as coletas das larvas e pupas de simulídeos foram utilizados substratos artificiais, instalados nos arroios por períodos de 14 dias. Em todos os pontos de amostragens foram feitas coletas simultâneas de água para análise físicoquímica e microbiológica. Na área mais conservada foram coletadas onze espécies com as seguintes freqüências: Psaroniocompsa incrustata (42,95\%), P. auripellita (17,66\%), Chirostilbia pertinax (16,86\%), Inaequalium subclavibranchium (8,43\%), I. nogueirai (5,80\%), P. anamariae (3,69\%), I. clavibranchium (1,58\%), C. riograndense $(0,92 \%)$, Lutzsimulium hirticosta $(0,92 \%)$, I. botulibranchium $(0,79 \%)$, Thyrsopelma itaunense $(0,40 \%)$. Na área de maior impacto foram coletadas apenas seis espécies: C. pertinax $(84,31 \%)$, C. riograndense $(7,52 \%)$, T. itaunense (4,68\%), P. incrustata (2,94\%), I. subclavibranchium (0,33\%), Ectemnaspis dinellii (0,22\%). As concentrações de Nitrato e Nitrito na água foram os fatores que melhor permitem distinguir os pontos amostrados. A concentração de nitrato esteve significativamente relacionada com C. pertinax $\left(\mathrm{r}^{2}=0,54 ; \mathrm{P}<0,03\right)$ e com T. itaunense $\left(\mathrm{r}^{2}=0,55 ; \mathrm{P}<0,03\right)$ e nitrito com $C$. riograndense $\left(\mathrm{r}^{2}=0,64 ; \mathrm{P}<0,02\right)$. Essas informações podem ser úteis aos programas de controle integrado dos simulídeos, atualmente em execução em pelo menos 170 municípios no Rio Grande do Sul.

PALAVRAS-CHAVE. Borrachudos; Nematocera; Neotropical; poluição orgânica; Simuliidae.

Os estudos de variações na abundância dos simulídeos e distribuição local das espécies são importantes, pois, através da atividade hematofágica, esses insetos interferem na qualidade de vida das pessoas. As picadas dos adultos de determinadas espécies podem causar sérias reações alérgicas. Dentre essas, Chirostilbia pertinax (Kollar 1832) é uma das mais importantes e causa prejuízos econômicos principalmente em agropecuária e no turismo (Ruas Neto \& Matias 1985; Strieder \& Corseuil 1992). As perdas econômicas ocasionadas pelas espécies zoófilas são difíceis de serem avaliadas, podem estar relacionadas com perdas de peso dos animais, redução na produção de leite e transmissão de doenças específicas aos animais domésticos ou diretamente ao homem (Fredeen 1977).

A distribuição e a abundância das espécies podem ser influenciadas pela vazão dos cursos d'água, disponibilidade de substratos para a fixação das formas imaturas (ovos, larvas e pupas), substâncias dissolvidas na água, composição da vegetação ciliar, assim como, pelas ações do homem nas áreas limítrofes (Ross \& Merritt 1987; Moreira et al. 1994; Hamada \& McCreadie 1999; Hamada \& Adler 2001; Strieder 2002; Strieder et al. 2002).

Entre as 32 espécies de Simuliidae que ocorrem no Rio Grande do Sul, Chirostilbia pertinax parece ser uma das mais favorecidas com o aumento da poluição dos arroios em áreas rurais. Um dos problemas ambientais que favorecem o desequilíbrio populacional das espécies é o elevado despejo de matéria orgânica nos cursos d'água, principalmente devido ao tratamento inadequado dos dejetos oriundos da criação de 
animais domésticos. Os conhecimentos sobre a distribuição local e a diversidade das formas imaturas de Simuliidae nos cursos d'água são fundamentais para podermos distinguir os padrões de abundância associados a perturbações ambientais de origem antropogênica daqueles gerados por processos naturais (Strieder et al. 2002; Strieder 2005).

A expansão da avicultura e suinocultura trouxe a produção de grandes quantidades de dejetos, que pela falta de tratamento adequado se transformou na maior fonte poluidora dos cursos hídricos em várias regiões do Brasil. Estima-se que a quantidade de dejetos líquidos produzidos ao ano por uma matriz suína e sua prole, considerando o sistema de produção em ciclo completo, seja de 23,7 metros cúbicos. Aproximadamente 45 a $60 \%$ do nitrogênio, 50 a $80 \%$ do fósforo e cálcio, 70 a $95 \%$ do cobre, zinco, potássio, sódio, magnésio, manganês e ferro consumidos são excretados pelos suínos. Embora a eficiência das aves para retenção de nitrogênio e fósforo seja maior do que a dos suínos, cada frango de corte abatido com peso médio de $2,5 \mathrm{Kg}$, terá excretado em torno de $100 \mathrm{~g}$ de nitrogênio e $10 \mathrm{~g}$ de fósforo (Ludke \& Ludke 2003).

O manejo de dejetos de animais apresenta características que afetam todas as criações intensivas. Os problemas ambientais relacionados com a avicultura e suinocultura se expressam de forma mais intensa em algumas regiões. Nesse contexto, o presente trabalho teve como objetivo investigar a influência dessas culturas sobre a distribuição local, abundância e diversidade de simulídeos, em quatro cursos d'água localizados em uma mesma bacia hidrográfica, na região da Encosta Inferior do Nordeste, no Rio Grande do Sul.

\section{MATERIAL E MÉTODOS}

Área de Estudo, Coleta e Análise do material. A investigação foi desenvolvida no curso médio-superior da bacia hidrográfica do rio Caí pertencente à região hidrográfica do Guaíba. As amostragens foram realizadas no arroio Feitoria e num dos seus afluentes, arroio da Mata, situados entre os paralelos $29^{\circ} 32^{\prime} \mathrm{S}$ e $29^{\circ} 35^{\prime} \mathrm{S}$ e os meridianos $50^{\circ} 59^{\prime} \mathrm{W}$ e $51^{\circ} 00^{\prime} \mathrm{W}$ (ambiente pouco alterado pelas atividades do homem) e no arroio Columbio e São Salvador, situados entre os paralelos $29^{\circ} 23^{\prime} \mathrm{S}$ e $29^{\circ} 28^{\prime} \mathrm{S}$ e os meridianos $51^{\circ} 20^{\prime} \mathrm{W}$ e $51^{\circ} 31^{\prime} \mathrm{W}$ (ambiente de maior impacto, com grande produção de aves e suínos).

Na sub-bacia do arroio Feitoria as coletas foram realizados no município de Sapiranga, na localidade de Picada Verão. Nesse local, existem paisagens variadas, decorrentes da diversidade de ambientes e pouco uso da terra. Embora composta principalmente por florestas secundárias, ainda está presente a vegetação das faixas de preservação permanente, de 30 a 50 metros ao longo dos cursos d'água. A atividade agrícola está baseada em policultura e a criação de animais encontra-se restrita para auto-subsistência. Existe na região um crescente investimento em ecoturismo, motivado pela qualidade do ambiente, que se encontra em grande parte ainda conservado.

No arroio Columbio, as coletas foram realizadas no município de Barão, Linha Francesa Baixa e no arroio São
Salvador, em Salvador do Sul, na localidade de Júlio de Castilhos. A atividade econômica predominante nessas subbacias é a agricultura, além da intensa avicultura e suinocultura industrial. Os problemas ambientais mais críticos observados nos segmentos dos arroios amostrados estão associados à retirada da mata ciliar, erosão do solo e à contaminação da água com resíduos orgânicos, especialmente os decorrentes do tratamento inadequado dos dejetos oriundos da criação de animais.

De acordo com a classificação de Köppen, o clima predominante na região é o subtropical úmido com precipitações durante todo ano, sofrendo a influência de massas de ar tropicais e polar-atlânticas. A precipitação média anual é variável, atingindo $2.100 \mathrm{~mm} /$ ano nas nascentes (Rio Grande do Sul 1994). A cobertura florestal original segundo SEPLAN/IBGE (1986), é do tipo Floresta Estacional Decidual.

As amostragens de simulídeos desenvolveram-se de 22 de agosto a 26 de setembro de 2001, sendo realizadas coletas em três datas, com o objetivo de amostrar as espécies mais representativas nas duas áreas de estudo.

$\mathrm{Na}$ coleta das larvas e pupas foram utilizados substratos artificiais, confeccionados com cordões de polipropileno com $20 \mathrm{~cm}$ de comprimento, parcialmente desfiados. Em cada uma das três amostragens foram instalados dez substratos nos quatro arroios investigados e após 14 dias todo o material foi recolhido, sendo acondicionado em vidros contendo álcool $96^{\circ} \mathrm{GL}$, etiquetados e levados ao laboratório para identificação.

Em todos os pontos de estudo foram feitas coletas simultâneas de água para análise físico-química e microbiológica. As amostras de água foram preservadas e analisadas de acordo com as normas técnicas estabelecidas em APHA (1998). Para determinação de oxigênio dissolvido, demanda bioquímica de oxigênio e análises colimétricas, coletou-se água em frascos de vidro $(250 \mathrm{~mL})$ e para os demais parâmetros foram utilizadas garrafas de polietileno de $1.000 \mathrm{~mL}$. As análises foram realizadas nos laboratórios de Geoquímica e de Microbiologia da Universidade do Vale do Rio dos Sinos.

Os caracteres de diferenciação das larvas dos simulídeos são de difícil observação, o que dificulta a identificação das espécies principalmente nos estádios larvais iniciais. Por isso, apenas as pupas e as larvas do último estádio, caracterizadas pela presença de histoblasto branquial bem desenvolvido, foram consideradas nas análises.

No presente trabalho seguiu-se a posição taxonômica que propõem a elevação dos subgêneros ao nível de gênero em Simuliidae (Newman 1834) conforme nomenclatura utilizada por Py-Daniel \& Moreira Sampaio (1994).

Utilizou-se o programa PC-ORD 4.20 (McCune \& Mefford 1999) para executar uma análise de correspondência canônica com os valores de abundância das espécies e também das variáveis ambientais. Essa é uma análise exploratória que agrupa os sítios em função da abundância das espécies e indica potenciais relações entre essas espécies e as variáveis ambientais. Uma análise de regressão múltipla foi utilizada para avaliar a correlação entre variáveis ambientais potencialmente importantes para a distribuição das espécies (indicadas pela 
Tabela I. Somatório das formas imaturas de Simuliidae obtidas nas amostragens realizadas em quatro arroios localizados em diferentes ambientes na bacia do rio Caí, no Rio Grande do Sul.

\begin{tabular}{|c|c|c|c|c|c|}
\hline & \multicolumn{2}{|c|}{ Área de reduzido impacto } & \multicolumn{2}{|c|}{ Área de maior impacto } & \multirow{2}{*}{ Total } \\
\hline & Ar. Feitoria & Ar. da Mata & Ar. Salvador & Ar. Columbio & \\
\hline Larvas em estádios iniciais & 2.553 & 1.648 & 5.738 & 1.568 & 11.507 \\
\hline Larvas em último estádio & 259 & 99 & 310 & 175 & 843 \\
\hline Pupas & 295 & 106 & 287 & 146 & 834 \\
\hline Total & 3.107 & 1.853 & 6.335 & 1.889 & 13.184 \\
\hline
\end{tabular}

ACC) e a abundância das mesmas. Essa análise permite predições mais acuradas e pode ser utilizada após a análise exploratória dos dados feita com uma análise de correspondência canônica (Braak 1995). A variável dependente considerada foi a abundância de uma espécie em particular em cada sítio e as variáveis independentes foram as variáveis ambientais.

\section{RESULTADOS E DISCUSSÃO}

Nas amostragens das formas imaturas de simulídeos nos quatro arroios estudados, na bacia hidrográfica do rio Caí, foram coletadas 12.350 larvas e 834 pupas, totalizando 13.184 exemplares pertencentes a 12 espécies, incluídas em seis gêneros: Lutzsimulium hirticosta (Lutz, 1909), Inaequalium botulibranchium (Lutz, 1910), I. clavibranchium (Lutz, 1910), I. nogueirai (d'Andretta \& González, 1962), I. subclavibranchium (Lutz, 1910), Psaroniocompsa anamariae (Vulcano, 1926), P. auripellita (Enderlein, 1933), P. incrustata (Lutz, 1910), Chirostilbia pertinax (Kollar, 1832), C. riograndense (Py-Daniel, Souza \& Caldas, 1988), Ectemnaspis dinellii (Joan, 1912) e Thyrsopelma itaunense (d'Andretta \& González, 1964).

Considerando os números totais de larvas e pupas obtidos (Tabela I), as maiores diferenças foram observadas entre o arroio São Salvador e o Feitoria, onde foram coletados 6.335 e 3.107 indivíduos respectivamente. Esses resultados podem ser atribuídos ao distinto estado de conservação ambiental e a qualidade da água dos arroios nas duas áreas investigadas.

$\mathrm{Na}$ área de maior impacto foi obtida a maior porcentagem de simulídeos $(62,4 \%)$, com 8.224 dos indivíduos coletados e constou de seis espécies, com as seguintes freqüências: $C$. pertinax $(84,3 \%)$, C. riograndense $(7,5 \%)$, T. itaunense $(4,7 \%)$, P. incrustata (3,0\%), I. subclavibranchium $(0,3 \%)$ e E. dinellii $(0,2 \%)$.

$\mathrm{Na}$ área menos alterada pelas atividades do homem foram coletados 4.960 indivíduos, correspondendo a menor porcentagem $(37,6 \%)$, pertencentes a 11 espécies, com as seguintes freqüências: $P$. incrustata $(42,9 \%), P$. auripellita (17,7\%), C. pertinax (16,9\%), I. subclavibranchium (8,4\%), I. nogueirai $(5,8)$, P. anamariae $(3,7 \%)$, I. clavibranchium (1,6\%), C. riograndense $(0,9 \%)$, L. hirticosta $(0,9 \%), I$. botulibranchium $(0,8 \%)$ e T. itaunense $(0,4 \%)$.

Comparando os somatórios de larvas em último estádio e pupas (Tabela II), podemos considerar que o grau de conservação dos arroios também influencia os valores de riqueza e abundância das espécies. Quanto à riqueza, foi observada uma maior diferença entre os arroios de menor porte, com ocorrência de nove espécies no arroio da Mata e apenas quatro no Columbio.

Do total de 12 espécies coletadas, apenas $E$. dinellii foi exclusiva da área de maior impacto, seis ocorreram exclusivamente na área com reduzido impacto: $L$. hirticosta, $I$. botulibranchium, I. clavibranchium, I. nogueirai, P.

Tabela II. Somatórios de larvas em último estádio (L) e pupas (P) das espécies de Simuliidae coletadas nos quatro arroios estudados na bacia do rio Caí, no Rio Grande do Sul.

\begin{tabular}{|c|c|c|c|c|c|c|c|c|c|}
\hline \multirow{3}{*}{ Espécies } & \multicolumn{4}{|c|}{ Área de reduzido impacto } & \multicolumn{4}{|c|}{ Área de maior impacto } & \multirow{3}{*}{$\begin{array}{l}\text { Total } \\
\mathrm{L}+\mathrm{P}\end{array}$} \\
\hline & \multicolumn{2}{|c|}{ Ar. Feitoria } & \multicolumn{2}{|c|}{ Ar. da Mata } & \multicolumn{2}{|c|}{ Ar. Salvador } & \multicolumn{2}{|c|}{ Ar. Columbio } & \\
\hline & $\mathrm{L}$ & $\mathrm{P}$ & $\mathrm{L}$ & $\mathrm{P}$ & $\mathrm{L}$ & $\mathrm{P}$ & $\mathrm{L}$ & $\mathrm{P}$ & \\
\hline Lutzsimulium hirticosta & 0 & 0 & 3 & 4 & 0 & 0 & 0 & 0 & 7 \\
\hline Inaequalium botulibranchium & 0 & 0 & 4 & 2 & 0 & 0 & 0 & 0 & 6 \\
\hline Inaequalium clavibranchium & 0 & 0 & 6 & 6 & 0 & 0 & 0 & 0 & 12 \\
\hline Inaequalium nogueirai & 6 & 8 & 13 & 17 & 0 & 0 & 0 & 0 & 44 \\
\hline Inaequalium subclavibranchium & 8 & 9 & 19 & 28 & 2 & 1 & 0 & 0 & 67 \\
\hline Psaroniocompsa anamariae & 0 & 0 & 17 & 11 & 0 & 0 & 0 & 0 & 28 \\
\hline Psaroniocompsa auripellita & 66 & 68 & 0 & 0 & 0 & 0 & 0 & 0 & 134 \\
\hline Psaroniocompsa incrustata & 135 & 137 & 24 & 30 & 10 & 8 & 7 & 2 & 353 \\
\hline Chirostilbia pertinax & 43 & 71 & 6 & 8 & 268 & 274 & 113 & 119 & 902 \\
\hline Chirostilbia riograndense & 0 & 0 & 7 & 0 & 0 & 1 & 45 & 23 & 76 \\
\hline Thyrsopelma itaunense & 1 & 2 & 0 & 0 & 28 & 3 & 10 & 2 & 46 \\
\hline Ectemnaspis dinellii & 0 & 0 & 0 & 0 & 2 & 0 & 0 & 0 & 2 \\
\hline Total & 259 & 295 & 99 & 106 & 310 & 287 & 175 & 146 & 1.677 \\
\hline
\end{tabular}


Tabela III. Condições físicas, químicas e microbiológicas da água nos quatro arroios estudados, na bacia do rio Caí, Rio Grande do Sul, Brasil, no período de 22 de agosto a 26 de setembro de 2001 .

\begin{tabular}{|c|c|c|c|c|}
\hline \multirow{2}{*}{ Variáveis } & \multicolumn{2}{|c|}{ Área de reduzido impacto } & \multicolumn{2}{|c|}{ Área de maior impacto } \\
\hline & Ar. Feitoria & Ar. da Mata & Ar. Salvador & Ar. Columbio \\
\hline Nitrato (mg/L NO3-N) & $* 0,63(0,46-0,82)$ & $0,52(0,43-0,69)$ & $1,75(1,46-1,88)$ & $1,00(0,74-1,31)$ \\
\hline Nitrito $(\mu \mathrm{g} / \mathrm{L}$ NO2-N) & $6,9(6,7-7,3)$ & $7,4(6,7-9,3)$ & $49,7(9,9-205,1)$ & $21,6(8,5-36,0)$ \\
\hline Demanda Bioquímica de & $2,0(2,0-2,0)$ & $2,0(2,0-2,0)$ & $2,8(2,0-6,4)$ & $2,2(2,0-2,8)$ \\
\hline Oxigênio-DBO (mg/L O2) & & & & \\
\hline $\begin{array}{l}\text { Demanda química de } \\
\text { oxigênio-DQO (mg/L O2) }\end{array}$ & $7,6(5,0-18,6)$ & $6,6(5,0-12,6)$ & $17,7(5,0-32,2)$ & $10,9(5,0-20,9)$ \\
\hline $\begin{array}{l}\text { Sólidos Totais Voláteis } \\
(\mathrm{mg} / \mathrm{L})\end{array}$ & $13,2(12,4-14,0)$ & $14,77(12,8-17,9)$ & $18,2(11,0-28,5)$ & $21,0(19,6-22,4)$ \\
\hline $\begin{array}{l}\text { Sólidos Totais Dissolvidos } \\
(\mathrm{mg} / \mathrm{L})\end{array}$ & $34,3(20,0-45,7)$ & $38,8(15,7-56,5)$ & $102,6(82,3-121,3)$ & $98,4(86,5-119,9)$ \\
\hline Coliformes Fecais & $4,9 \times 10^{3}$ & $2,0 \times 10^{3}$ & $1,2 \times 10^{4}$ & $4,4 \times 10^{4}$ \\
\hline$(\mathrm{Nmp} / 100 \mathrm{~mL})$ & $\left(3,0 \times 10^{2}-2,5 \times 10^{4}\right)$ & $\left(3,1 \times 10^{2}-6,6 \times 10^{3}\right)$ & $\left(5,2 \times 10^{2}-3,5 \times 10^{4}\right)$ & $\left(5,2 \times 10^{2}-1,2 \times 10^{5}\right)$ \\
\hline Coliformes Totais & $1,9 \times 10^{5}$ & $1,6 \times 10^{5}$ & $3,2 \times 10^{5}$ & $4,6 \times 10^{5}$ \\
\hline$(\mathrm{Nmp} / 100 \mathrm{~mL})$ & $\left(6,1 \times 10^{2}-5,7 \times 10^{5}\right)$ & $\left(9,3 \times 10^{2}-8,1 \times 10^{5}\right)$ & $\left(3,1 \times 10^{4}-8,7 \times 10^{5}\right)$ & $\left(3,9 \times 10^{4}-2,4 \times 10^{6}\right)$ \\
\hline
\end{tabular}

*: médias do período e, entre parênteses, mínimas e máximas.

anamariae, $P$. auripellita e cinco foram comuns às duas áreas: $C$. pertinax, $C$. riograndense, $T$. itaunense, $P$. incrustata e $I$. subclavibranchium.

Os valores obtidos na análise da água (DBO, DQO, Nitrato, Nitrito, Sólidos totais dissolvidos, Coliformes totais e Coliformes fecais) foram maiores nos arroios localizados na área com intensa produção de aves e suínos. Entre os fatores que melhor permitem distinguir os arroios destacam-se as concentrações de Nitrato e Nitrito (Tabela III).

A análise de correspondência canônica indicou uma clara distinção entre os pontos amostrados nos diferentes arroios. Ao longo do primeiro eixo (autovalor $=0,641 ; 37,8 \%$ da variância total) os pontos localizados nos arroios mais impactados ficaram agrupados e distantes dos pontos localizados nos arroios menos impactados (Fig. 1). Já o segundo eixo foi bem menos importante para a ordenação dos pontos (autovalor $=0,130 ; 7,6 \%$ da variância total). Houve também espécies claramente associadas aos arroios mais degradados, como C. pertinax, C. riograndense, T. itaunense e $E$. dinelli e espécies associadas ao ambiente menos alterados pelas atividades do homem, como L. hirticosta, I. botulibranchium, I. clavibranchium, I. nogueirai, $P$. anamariae, $P$. auripellita.

Como a análise de correspondência canônica indicou o papel preponderante da concentração de nitrato e de nitrito, esses parâmetros foram usados com variáveis independentes na análise de regressão múltipla. Como variáveis dependentes foram utilizadas a riqueza total, a abundância total, e a abundância das cinco espécies que estiveram presentes em pelo menos metade dos pontos amostrados. Para três dessas espécies houve uma correlação significativa entre os parâmetros ambientais e abundância (Fig. 2). Concentração de nitrato foi o parâmetro significativamente correlacionado com a ocorrência de $C$. pertinax $\left(\mathrm{r}^{2}=0,54 ; \mathrm{P}<0,03\right)$ e com $T$. itaunense $\left(\mathrm{r}^{2}=0,55 ; \mathrm{P}<0,03\right)$ e a concentração de nitrito esteve significativamente correlacionada com a ocorrência de $C$. riograndense $\left(\mathrm{r}^{2}=0,64 ; \mathrm{P}<0,02\right)$. As equações dessas regressões são: $C$. pertinax: $\mathrm{Y}=-42,00+97.6915$ nitrato; $T$. itaunense $\mathrm{Y}=-3.97338+5.51245$ nitrato e $C$. riograndense $\mathrm{Y}=$ $-0.80252+1.05878$ nitrito. Os resultados indicaram que não havia uma correlação significativa dos parâmetros ambientais com a riqueza total $\left(\mathrm{r}^{2}=0,14 ; \mathrm{P}>0,5\right)$, com a abundância total dos simulídeos $\left(\mathrm{r}^{2}=0,11 \mathrm{P}>0,5\right)$ ou com as espécies $P$. incrustata $\left(\mathrm{r}^{2}=0,09 ; \mathrm{P}>0,6\right)$ e I. subclavibranchium $\left(\mathrm{r}^{2}=0,38\right.$; $\mathrm{P}>0,1)$.

C. pertinax foi a espécie mais abundante, ocorreu em todos os pontos amostrados e prosperou nos arroios com maior poluição orgânica e degradação ambiental (Fig. 3). No global, $85,8 \%$ dos indivíduos dessa espécie foram coletados na área de maior produção de aves e suínos. Esses dados estão em conformidade com os resultados de outro estudo desenvolvido

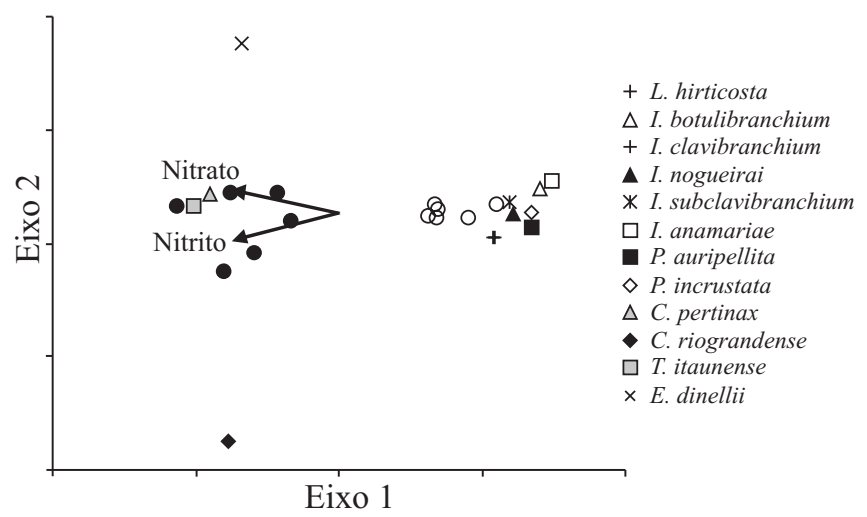

Fig. 1. Análise de Correspondência Canônica. Arroios mais impactados estão representados por círculos fechados e os arroios menos impactados por círculos abertos. Também estão indicadas as espécies e os parâmetros ambientais mais relevantes (setas). 

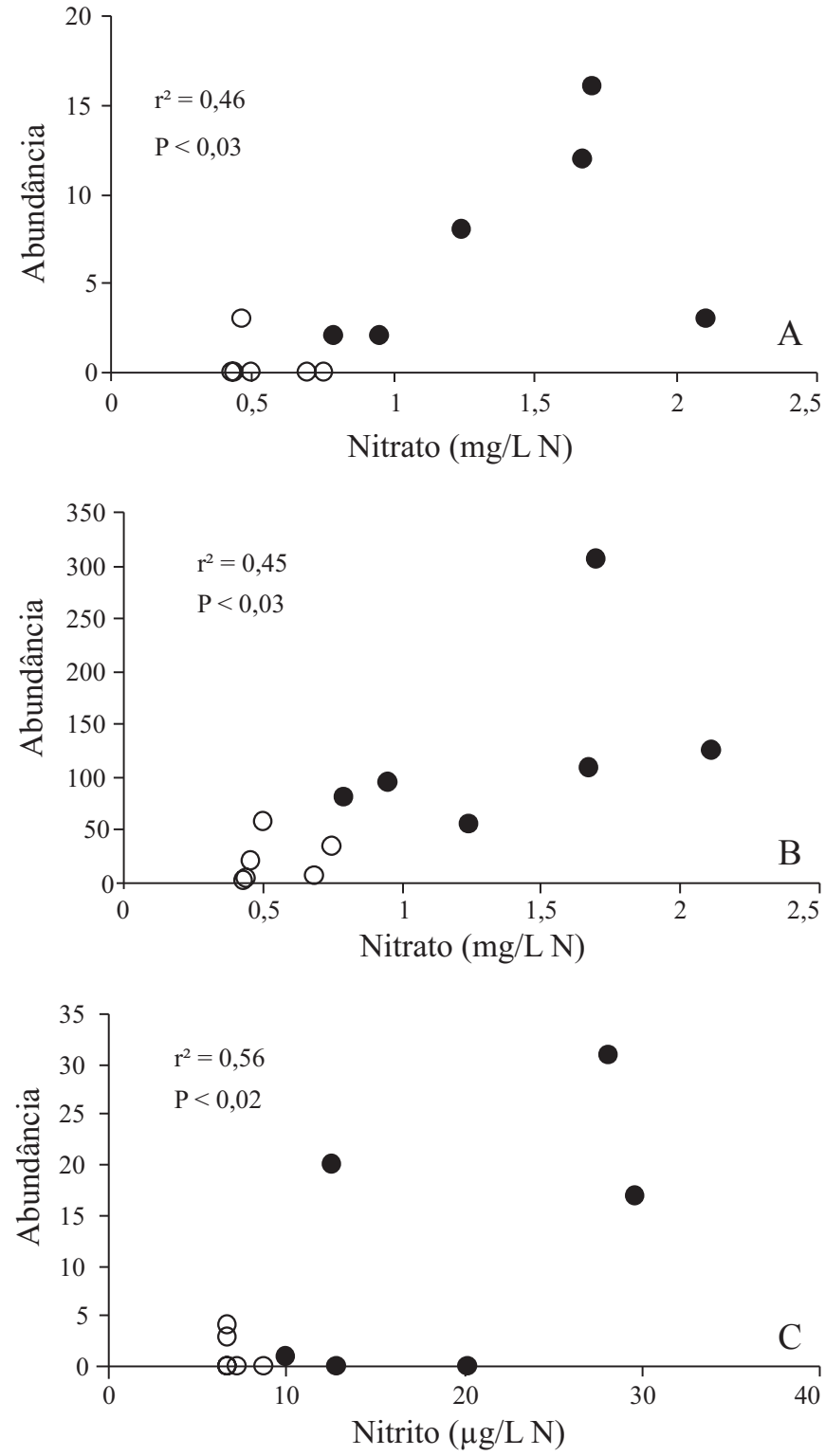

Fig. 2. Relação entre concentração de nitrato e de nitrito e a abundância de (A) Chirostilbia pertinax, (B) Thyrsopelma itaunense e (C) Chirostilbia riograndense. Arroios mais impactados estão representados por círculos fechados e os arroios menos impactados por círculos abertos. Também estão indicados os valores de $\mathrm{r}^{2} \mathrm{e}$ de $\mathrm{P}$ gerais para cada regressão.

na mesma região sobre a atividade hematofágica dos adultos, onde essa espécie é a que mais perturba o homem e os animais domésticos (Strieder \& Corseuil 1992).

Nos Estados Unidos e Canadá, a abundância das larvas de simulídeos também foi relacionada com impactos antrópicos, principalmente com o aumento de matéria orgânica nos rios, em decorrência do lançamento de resíduos domésticos, agrícolas e industriais (Fredeen 1964; EPA 1976).

Os dados do presente trabalho revelam que as espécies de simulídeos são influenciadas de forma diferente pelas alterações da estrutura do hábitat e pela poluição orgânica dos cursos d'água onde se criam as formas imaturas. Esses resultados concordam com diversos autores que têm relatado a formação de grupos de espécies de acordo com as características do ambiente aquático selecionado pelas fêmeas, durante o processo de postura (Ross \& Merritt 1987; Hamada \& McCreadie 1999; Hamada \& Adler 2001).

Um dos fatores envolvidos na distribuição e abundância de C. pertinax pode estar relacionado com o aporte orgânico proporcionado aos cursos hídricos devido ao tratamento inadequado dos dejetos orgânicos oriundos da criação de animais domésticos, principalmente na suinocultura, que se encontra ainda em plena expansão na região Sul do Brasil. A alta freqüência de larvas e pupas dessa espécie nos arroios Columbio e São Salvador parece estar relacionada com a concentração de nitrato na água e como conseqüência o maior número de adultos gerados causa incômodos pela intensa atividade hematofágica nos humanos.

Várias outros impactos ambientais podem contribuir para o desequilíbrio populacional dos simulídeos, como as alterações no leito de córregos e rios, o uso e ocupação do solo em áreas às suas margens e a destruição da vegetação ciliar nativa. Essas atividades podem resultar no aumento populacional de algumas espécies e na redução da biodiversidade, com eliminação dos predadores naturais. Nesse contexto, a conservação da qualidade da água e a preservação da integridade biológica dos cursos hídricos deve receber destaque entre as ações a serem implementadas pelas equipes técnicas dos programas de controle dos simulídeos (Strieder 2005).

Para dimensionar corretamente o problema e alcançar uma maior eficiência no controle desses insetos, com o envolvimento da comunidade afetada, é fundamental que as equipes de trabalho conheçam as características ecológicas do desenvolvimento das formas imaturas no ambiente aquático. Esse conhecimento permitirá maior sucesso na reversão dos fatores ambientais responsáveis pelo desequilíbrio populacional das espécies hematófagas.

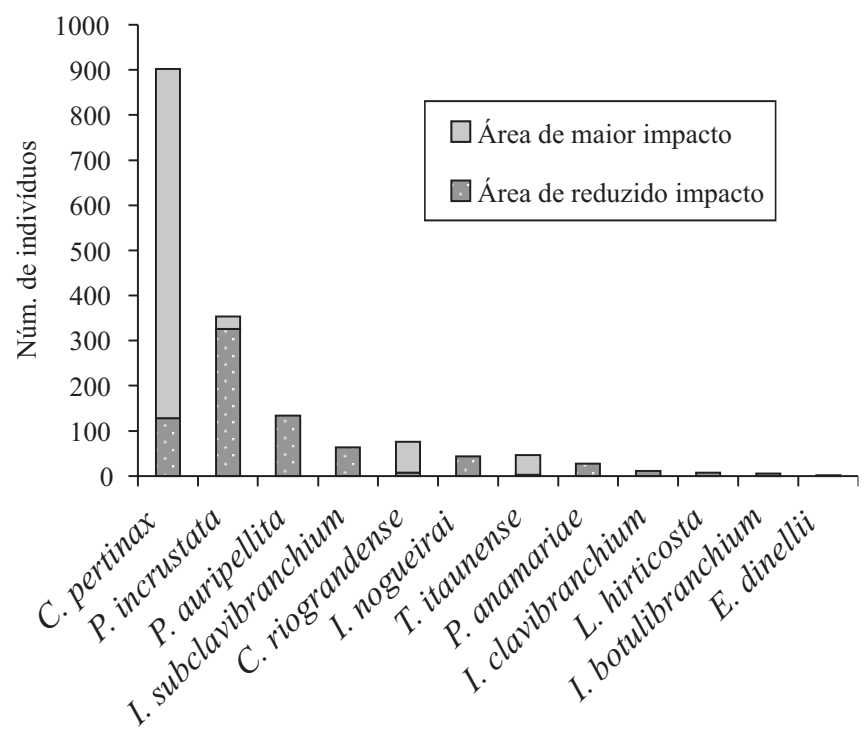

Fig. 3. Espécies de Simuliidae e proporções obtidas em dois ambientes de diferente ação antrópica na bacia hidrográfica do rio Caí, Rio Grande do Sul. 
Agradecimentos. À Fundação de Amparo à Pesquisa do Estado do Rio Grande do Sul - FAPERGS, o auxílio financeiro ao Projeto $\mathrm{n}^{\circ}$ 02/ 1406.3 e pela concessão de bolsa de Iniciação Científica. À Universidade do Vale do Rio dos Sinos - UNISINOS pelo apoio logístico. Ao Pe Edward G. F. Benya SJ pela revisão do "abstract".

\section{REFERÊNCIAS}

APHA-American Public Health Association 1998. Standard Methods for the Examination of Water and Wastewater. American Public Health Association, Washington, 20. edição. 1162 p.

Braak, C. J. F. 1995. Ordination. In: R. H. G. Jongman; C. J. F. Braak \& O. F. R. Van Tongeren (eds.). Data analysis in community and landscape ecology. Cambridge University Press, Cambridge. p. 91-173.

EPA-Environmental Protection Agency. 1976. Quality criteria for water. Washington, EPA. 501 p.

Fredeen, F. J. H. 1964. Bacteria as food for blackfly larvae (Dipera: Simuliidae) in laboratory cultures and in natural streams. Canadian Journal of Zoology 42: 527-548.

Fredeen, F. J. H. 1977. A review of the economic importance of black flies (Simuliidae) in Canada. Quaestiones Entomologicae 13: 219-229.

Hamada, N. \& J. W. McCreadie. 1999. Environmental factors associated with the distribution of Simulium perflavum Species-Group (Diptera: Simuliidae) from Brazilian Amazonia. Hydrobiologia, 397: 7178.

Hamada, N. \& P. H. Adler. 2001. Bionomia e chave para imaturos e adultos de Simulium (Diptera: Simuliidae) na Amazônia Central, Brasil. Acta Amazonica 31: 109-132.

Ludke, J. V. \& M. C. M. Ludke. 2003. Produção de suínos com ênfase na preservação do ambiente. Disponível em www.cnpsa.embrapa.br/ ?/artigos/2003/artigo-2003-n21.html. Acesso em 16 de nov. 2005.

McCune, B. \& M. J. Mefford. (1999) Multivariate Analysis of Ecological Data. Version 4.20. Mjm Software. Gleneden Beach, Oregon.

Moreira, G. R. P.; R. A. Pegoraro \& G. Sato. 1994. Influência de fatores abióticos sobre o desenvolvimento de Simulium nogueirai
D’Andretta \& Gonsález em um córrego da Mata Atlântica. Anais da Sociedade Entomológica do Brasil 23: 525-542.

Py-Daniel, V. \& R. T. M. Sampaio. 1994. Jalacimgomyia gen.n. (Culicomorpha); a ressurreição de Gymnopaidinae; a eliminação do nível tribal; apresentação de novos caracteres e a redescrição dos estágios larval e pupal de Simulium colombaschense (Fabricius, 1787) (Diptera: Simuliidae). Memorias del Centro Amazónico para Investigación y Control de Enfermedades Tropicales CAICET 4: 101-148.

Rio Grande do Sul. 1994. Secretaria da Agricultura e Abastecimento; Centro Nacional da pesquisa do Trigo. Macrozoneamento Agroecológico e Econômico do Estado do Rio Grande do Sul Porto Alegre, $2 \mathrm{~V}$.

Ross, D. H. \& R. W. Merritt. 1987. Factors affecting larval black fly distributions and population dynamics. In: K. C. Kim \& R. W. Merritt, R. W. (eds.): Black flies: Ecology, population management and anotated world list. The Pennsylvania State University, University Park, Pennsylvania, USA. p. 90-108.

Ruas Neto, A. L. \& R. S. Matias. 1985. Controle integrado do Simulium (Chirostilbia) pertinax Kollar, 1832. A competição interespecífica como possível método de controle natural. Boletim da Saúde 12: $21-24$.

SEPLAN/IBGE. 1986. Levantamento de recursos naturais. Radambrasil. V 33. Rio de Janeiro. 791 p.

Strieder, M. N. 2002. Diversidade e distribuição de Simuliidae (Diptera, Nematocera) no gradiente longitudinal da bacia do rio Maquiné, RS, Brasil. Biociências 10: 127-137.

Strieder, M. N. 2004. Espécies de simulídeos (Diptera, Nematocera, Simuliidae) no Rio Grande do Sul, Brasil: distribuição geográfica. Entomologia y Vectores 11: 117-121.

Strieder, M. N. 2005. Controle eficiente dos borrachudos. Ciência Hoje 36: 70-71

Strieder, M. N. \& E. Corseuil. 1992. Atividades de hematofagia em Simuliidae (Diptera, Nematocera) na Picada Verão, Sapiranga, RS Brasil. Acta Biologica Leopoldensia 14: 75-98.

Strieder, M. N.; J. E. dos Santos \& A. M. O. Pes. 2002. Diversidade e distribuição de Simuliidae (Diptera, Nematocera) no gradiente longitudinal da bacia do rio dos Sinos, no Rio Grande do Sul, Brasil. Entomologia y Vectores 9: 527-540.

Recebido em 28/09/2004; aceito em 15/12/2005 